\title{
The innovation of accounting and certification of historic architectural monuments using BIM technology
}

\author{
Olga Kysil ${ }^{1}$, Raddamila Kosarevska ${ }^{2}$, Oleksii Levchenko ${ }^{3}$ \\ ${ }^{1}$ Department of Information Technology in Architecture; \\ Kyiv National University of Construction and Architecture; Povitroflotskyi Av. 31, 03037 Kyiv, Ukraine; \\ solomyab@gmail.com (DD 0000-0003-2873-6901 \\ 2 Department of Drawings and Paintings; Kyiv National University of Construction and Architecture; \\ Povitroflotskyi Av. 31, 03037 Kyiv, Ukraine; \\ e-mail:kosarevska.ro@knuba.edu.ua (D) 0000-0003-1076-0364 \\ ${ }_{3}^{3}$ Department of Information Technology in Architecture Kyiv National University of Construction \\ and Architecture; Povitroflotskyi Av. 3103037 Kyiv Ukraine; \\ levchenko.ov@knuba.edu.ua (iD)0000-0002-5254-2114
}

\begin{abstract}
Presented research shows Building Information Modeling (BIM) technology as a highly promising tool for architectural heritage conservation. Analyses of contemporary publications by BIM topic and HBIM (Historic Building Information Modeling), its specific division, are conducted. The usage of modern technology analysis for digitizing monuments along with the outdated 'manual' of accounting and passportization methods are executed, and a lack of automation of the above processes is observed. Additionally, the research reveals that during the operational period of historical objects, there was no method of fixing their architectural transformations. The necessity of automation of the abovementioned processes by the capabilities of the BIM technology is emphasized. Automation methods developed utilizing the BIM model properties as a relational database, are described. An example of the method implementation in architectural and construction software applications is given. The case uses the rules of filling in the state accounting card of Ukraine. Nonetheless, the automatic formation of a document like this by the standards of any country is underscored.
\end{abstract}

Keywords: $B I M, H B I M, B I M 4 \mathrm{D}$, the life cycle of a building, information modeling of historical buildings, cultural heritage objects, Allplan software

\section{Introduction}

In the current context of urbanization and rapid urban development, problems related to the protection of urban and architectural heritage, as well as their historical environment, are of great importance. The use of Building Information Modeling (BIM) technologies, and in particular Historic Building Information Modeling (HBIM), while monitoring the state of architectural heritage 
sites is a very effective tool for their comprehensive and complete preservation. However, it is not yet used for certification and for displaying changes (transformation or modification) of the architectural forms and elements of these objects that have occurred during the history of their operation.

Before the advent of the BIM technology, architects also redesigned at the level of urban infrastructure and individual clusters, including geometry, spatial relationships, and geographic information. Examples of such changes can be found in Bruno Fortier's work, in which the stages of the historical and urban development of Paris were visualized against the backdrop of its three-dimensional structure in the 1980s. [1] The work that combines the historical periods of operation of the Saint Sofia Cathedral in the $11^{\text {th }}$ and $17^{\text {th }}$ centuries presenst a similar concept [9]. Considerable works on the construction of the ensemble were carried out at the end of the $18^{\text {th }}$ century and continued until the middle of the next century. At that time, most of the current structures were built. The cathedral was renovated in the $19^{\text {th }}$ century. (Fig.2)

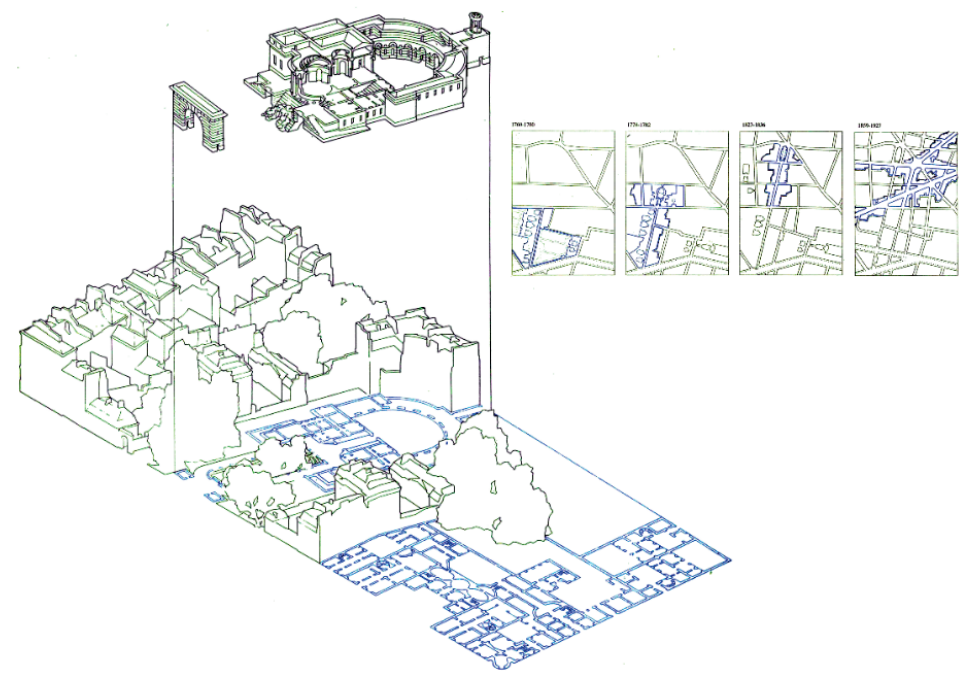

Fig. 1. The work of Bruno Fortier, L'atlasdeParis, source: [1]

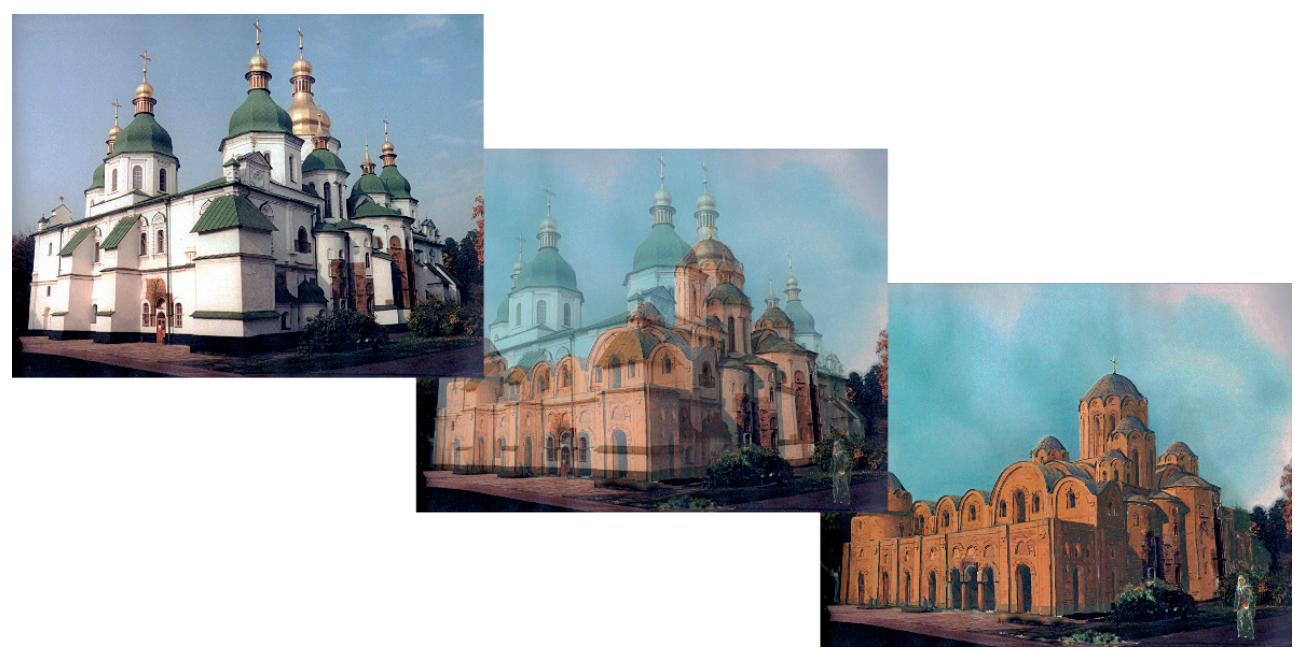

Fig. 2. Saint Sophia Cathedral, $11^{\text {th }}$ c. Transformations of architectural ensemble in time, source: [9] 


\section{The analysis of contemporary publications}

'Although BIM technology was created for the design and construction industry, nowadays its modeling tools and software tools open up new opportunities in the field of architectural heritage. At the same time, developments such as BIM can be applied to existing architectural monuments as well as to so-called "aggregate" information relating to selected historical periods, geographical areas, or architectural styles. "Technological bridge" between the past and the present created by this technology is, first of all, libraries of elements - make technologically straightforward ideas of "old" architecture in the new design and construction' [13].

The abovementioned libraries or "intellectual containers" will allow us not only to present a volumetric model of an architectural heritage object at all stages of its operational existence, but also to compare models of its original or present appearance with models of other periods of exploitation to "go" to the level of integration with the "digital" historical environment to discover the dynamics of their development or decline [13]. Studying the works of scientists on the use of BIM technologies in the protection, preservation, and management of objects of architectural heritage, we have found the following.

In their article dedicated to the concept and history of BIM, A. Bilyk, and M. Belyaev confirmed that its development was marked by the emergence of a fundamentally new approach in architectural and construction design (consisting of the creation of a computer model of a new building that covers all information about the future object) [8]. BIM is used both to refer to the building information model and the information modeling process. Graphisoft has even introduced the term 'VB' (Virtual Building), a virtual building. BIM is the process of generating and managing data from a single infrastructure over its life cycle using unique 3D and real-time dynamic building simulation software to reduce time and resource wasting in design and construction. This process is carried out in the information model of infrastructure (also designated BIM), which includes the geometry, spatial relationships, geographical information of the building, the number and properties of infrastructure components, etc. In collaboration with E. McGovern and S.Pavia, Maurice Murphy presented Historic BIM developed by the Historic BIM tool in quality of the new system of modeling historical buildings. The article provides a detailed description of the process of creating a three-dimensional parametric model of an architectural heritage object (remote data acquisition using a terrestrial laser scanner and digital cameras, combining image data and scanning, and converting the cloud point into a 3D model) and a library of architectural elements based on historical data, from Vitruvius to the architectural specimens of the eighteenth century [4].

The article by Oreni D., Bruman R., Georgopuslos A., and Cook B. illustrates the feasibility of using the HBIM tool in the field of protection and conservation of architectural monuments as an example of data collection implementation of element libraries (parametric, geometric, stylistic, historical, architectural) [6].

V. Talapov conducted an analysis of the value of information technologies for the monuments of history and architecture. He determined that BIM is a new way of fixing monuments, conducting their monitoring and study as a whole and parts, and the "electronic passport" of the monument, which can be used at all stages of its construction work. Talapov examined the relationship between the components of the information model of the architectural monument and the features of its creation through BIM technologies, as well as the importance of developing libraries of typical elements for historical buildings. The author states that typical elements should be the 'results' of historical eras, architectural styles, geographical zones, 
and buildings' contractural technologies. The article discusses the cultural connection between modern architecture and the periods of the past with the help of BIM [13].

Additionally, this study was based on a publication on a theoretical approach to the HBIM for conservation and management of architectural heritage objects, namely an overview of concepts and methods for storing architectural monuments in AEC. The foundation of HBIM technology is a database that can be used to collect and exchange information for monument registration and management [2]. According to Stefano Della Torre, bringing BIM technologies to the area of architectural monuments is a perspective area, although it raises some doubts about the effectiveness of its practical implementation - the process of preserving the architectural heritage is cardinally different from the process of construction of new structures. Any historical building is, first and foremost, a collection of architectural elements that emphasize its authenticity and architectural value. The reproduction of these elements in the BIM model can be done directly in its file model, as well as with the involvement of electronic libraries of typical aspects of historical architecture (in particular, Gothic-BIM, Renaissance-BIM, and Regens-BIM). Using these standard elements of libraries certainly make historical 3D models more realistic and attractive. Furthermore, such models should help to improve data sharing, not just be scripted videos. In his words, "the transition from drawings to BIM equals the transition from restoration, as an event, to protection, as a process." [7]. According to modern authors, the use of BIM technologies in restoration design requires the development of new methods and techniques for modeling the geometric shape of the architectural monument, namely:

1) a step-by-step model creation;

2) the 'parametricity' of typical architectural elements of libraries should be not only by design features (windows, columns, doors,profiles, etc.), but also by style and timing (classicism, modernity, or constructivism) and must contain elements or their compositions;

3 ) the modeling of various decorative elements (complex or small detail, which gives the building peculiarity), it is advisable to reproduce together with complex, that is, large and recurrent elements;

4) have a wider range of basic tools for BIM programs(the window tool is also suitable for modeling brick masonry niches and theprojecting profile for creating inter-floor curtain belts) [12].

The British article about BIM for Heritage, which is a guide for professionals working in heritage and construction, shows the potential benefits of BIM approach to its implementation in projects of heritage and efficiency of the building lifecycle management [5]. Moreover, research into digitization methods of existing building objects, that has been studied in the course of this work, indicates that the ground-based laser scanning technology can be beneficial for developing an inventory of an architectural object using BIM technology. It is essential to adhere to the proper methodology for collecting data, taking into account the principles of correct measurements and their subsequent analysis, as well as the processing of logged data using external software [14].

\section{Scientific novelty, goal and practical benefit of research}

The use of the BIM method in modeling an architectural monument is widely described in current research. Not only does it store spatial information and metadata, but it also provides the means of documenting changes such structures undergo. The scope varies 
The innovation of accounting and certification of historic architectural monuments...

from a simple documentation repository, through storage planning tools, to modeling and reconstruction tools [15].

However, existing research does not describe the method of automatically retrieving information for the registration and certification of historic sites and the automation of recording their changes over time in the accounting card.

This study improves the method of adding attributes to model tables of property of model elements [15], and also offers automation of receiving a card for accounting of architectural monuments. It is proposed to develop the HBIM model up to a 4D level (this level is used exclusively for new construction). BIM Model 4D chart data can also be displayed on the accounting card. Thus, the composition of the account card becomes complete and more detailed.

The scientific novelty of the research is to develop a method of automated formation of a card of accounting of historical objects by the standard of any state using the example of the Ukrainian card of accounting $[16,17]$. Also, filling the model with information to automatically generate the card develops the model to the BIM 4D level. This allows capturing an object's early transformations on time, as well as managing the life cycle of the object in the present and future state.

The described improvement in the HBIM method has both economic and social effects. This approach optimizes the operation of the facility, planning the necessary repairs, and changing the use of the upgrade function. The process of registration and accounting of architectural monuments is simplified against the background of significant improvement in accounting documents' quality and completeness.

The research benefits the field of professional work practically with historic building objects and the field of presentation and tourism. The 4D BIM level model software has tools for animated visualization of geometric transformations over time, which can be an exciting addition to the exhibits of architectural heritage museums.

\section{A method of using the BIM tool to create an architecture monument accounting card. Fixation of geometric transformations of an architectural monument in its life cycle by the BIM 4D method}

Currently, there are many software products in the field of BIM technology that can be used to accomplish complex tasks of protecting, preserving, and managing architectural heritage. The theoretical basis and relevance of using BIM for certification, restoration, and sometimes reconstruction of historical sites raises questions about methodological and functional tools that can be used to solve most of the tasks in the process.

The analytical method of comparing building model tools to BIM technology emits a fairly large number of software products. Still, it is possible to immediately identify the most common and versatile by rejecting specialized applications that perform a specific design or engineering function in the process of creating a BIM model.

Having a specific tool or toolkit in the app will help to identify the following branded products from software developers quickly: Autodesk with Revit, Nemetschek Group with Allplan, Graphisoft with Archicad, etc.

Investigating algorithmic features of the BIM design using the above products, an expert opinion can be expressed about the qualitative difference in model formation using 'stages', 
which is inherent in Revit and tools called 'reconstruction' in Allplan and Archicad applications. Using a systematic approach to the requirements of adapting additional information blocks to three-dimensional information, which is created to describe elements and characteristics of an object that cannot be modeled, the authors preferred the coverage of Allplan as the most adaptive tool for HBIM (Fig. 3).

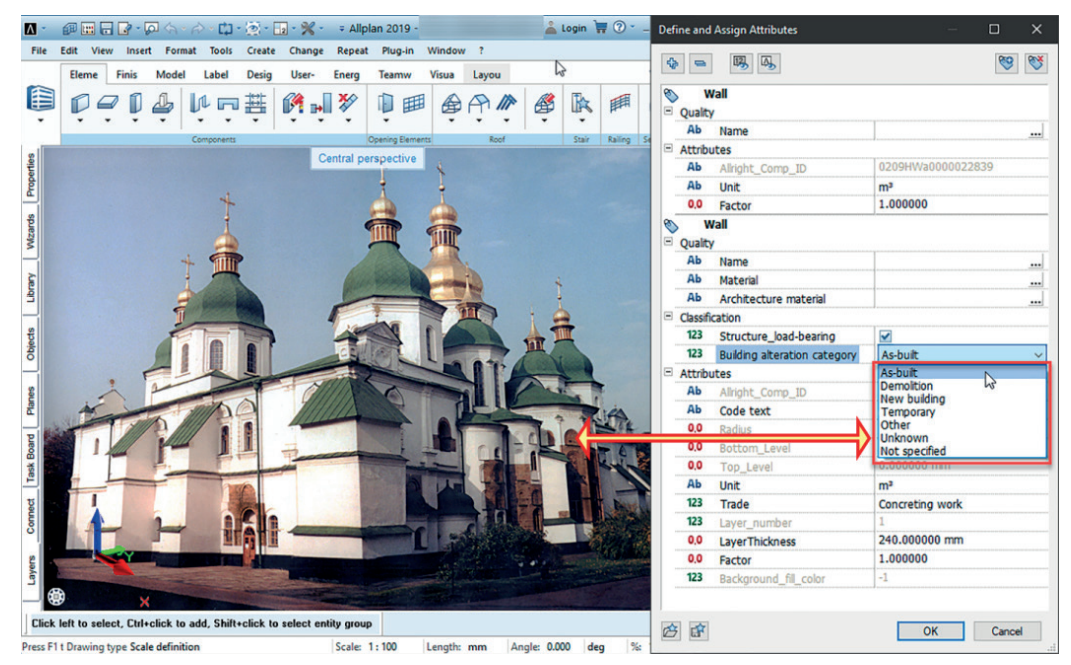

Fig. 3. BIM Model Properties by Reconstruction Attribute Setting. Made in Allplan 2019 software with Partnership license (own elaboration)

Due to the structure of attribution - a database that connects to all elements of the model allows to set layer properties (Fig. 4) to building structures during their studies. In this way, the database of building materials and mortars used in the construction of the architectural heritage monument will help to catalog other findings in archaeological and restoration studies.

The individual database elements in the BIM model are used not only to describe the construction volume. Their adjustment is supported in the 'Reconstruction' mode by processing linear objects, surfaces, objects of landscape nature, and separate premises with an indication of the area (separate area) of filling the openings (doors, windows, etc.) (Fig. 5). 

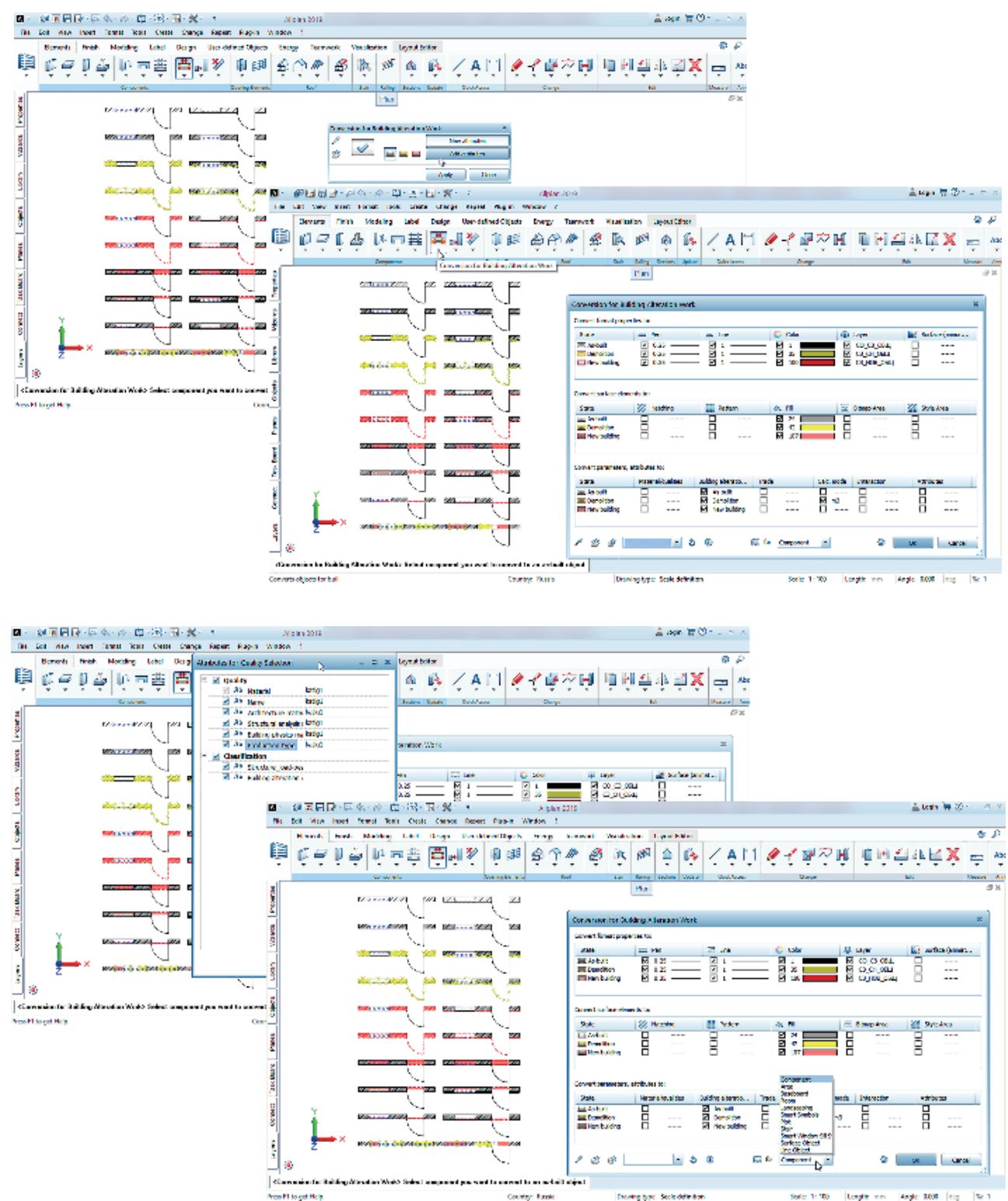

Fig. 4. "Reconstruction" of the installation of properties for individual BIM components (Made in Allplan 2019 software with Partnership license) (own elaboration)

Fig. 5. "Reconstruction" of components and databases of properties of building materials (Made in Allplan 2019 software with Partnership license) (own elaboration)

It is also necessary to note the peculiarities of the interaction of 3D elements with different parameters of the tool 'Reconstruction' (Fig. 6), which corresponds to the real situation of restoration and reconstruction work on the object of architectural heritage. 


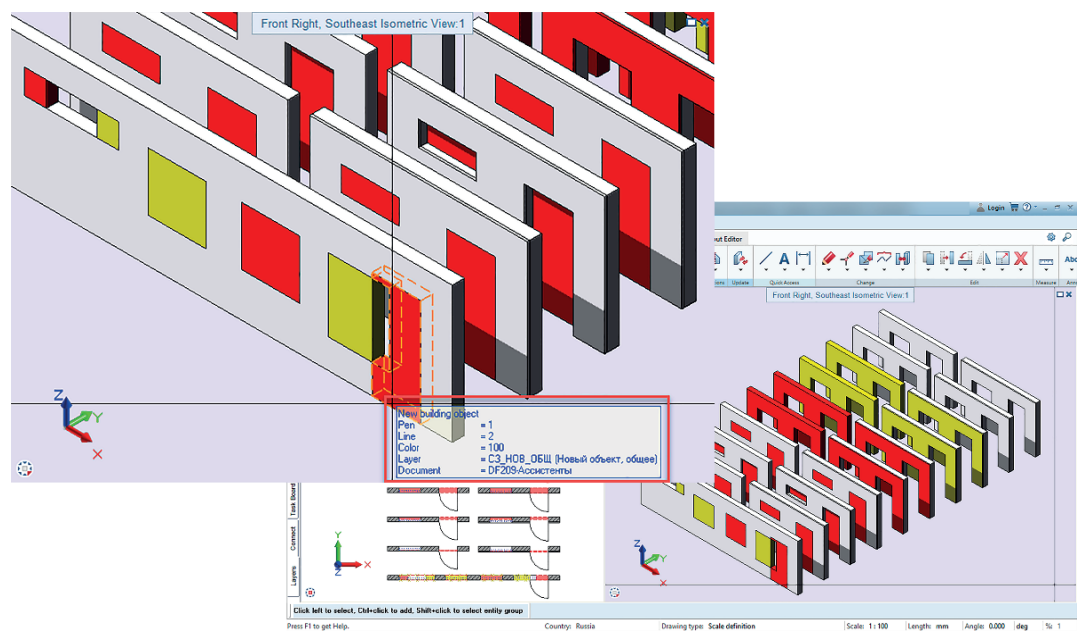

Fig. 6. "Reconstruction" of the installation of properties for individual BIM component (Made in Allplan 2019 software with Partnership license) (own elaboration)

The peculiarity of the life cycle of a historical building object in the HBIM model of the 4D level (Fig. 8) in comparison with the common life cycle of the modern building object (Fig. 7) should be emphasized.
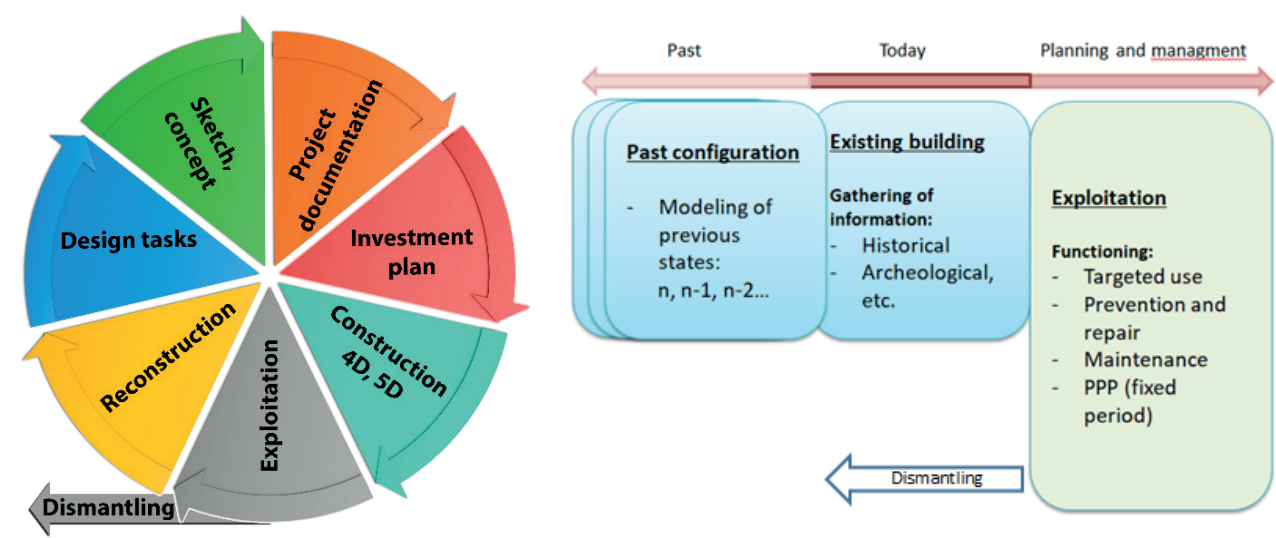

Fig. 7. Life cycle on the BIM concept (own elaboration)

Fig. 8. Life cycle on the HBIM concept (own elaboration)

Scientific research and innovation supplement the traditional HBIM-step approach, followed in the 4D form (Fig.9). Speaking about the new BIM model, 4D becomes a logical development of the model. This level is due to the availability of a certain amount of information, making it possible to create a construction schedule. That is, determining the order of gradual erection of building elements in reality. 


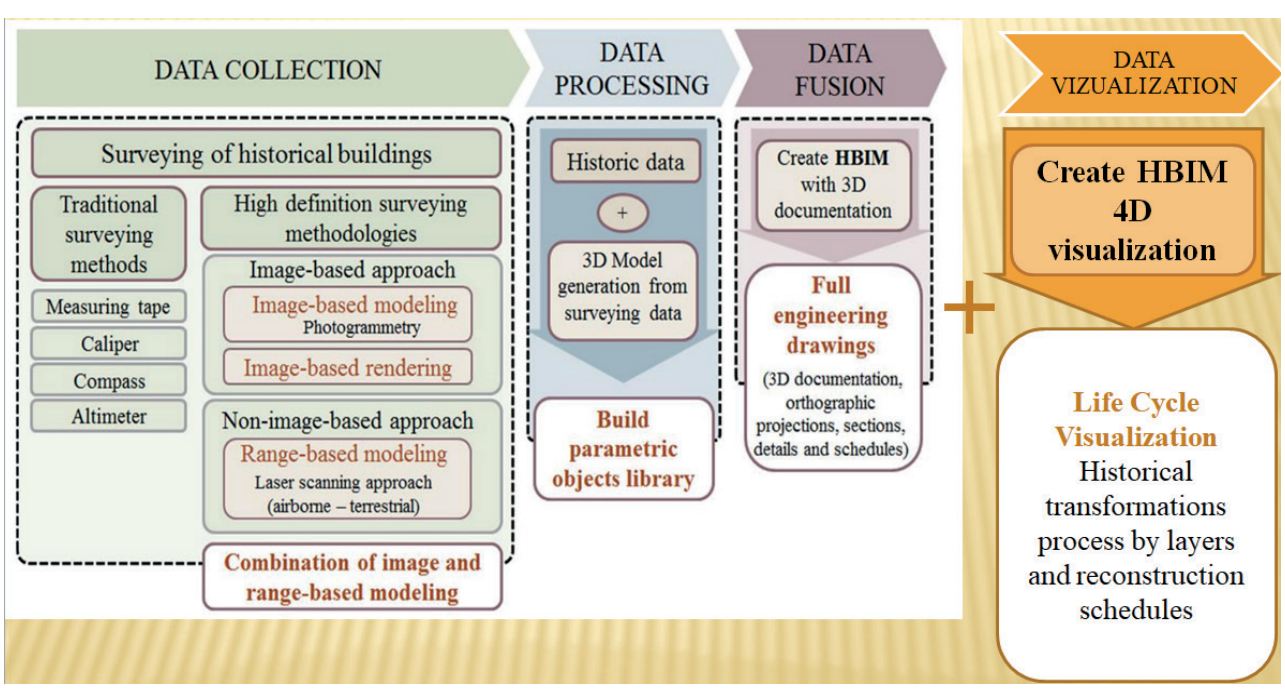

Fig. 9. Theoretical framework for HBIM approach (source:[2]), supplemented according to the results of this study (own elaboration)

The authors of the research made the reasonable assumption that in the case of an existing historical object and the existence of data on its peculiarities over the years, the algorithm for constructing a graph of the building of new elements can be considered as a graph of the disappearance of old elements, or their change. Thus, with a historical BIM model, the concept of a life cycle describes an often non-existent configuration and several iterations of restructuring. The addition of HBIM technology also provides an opportunity to keep track of the dynamics of the restoration and repair stages to maintain the architectural monument in proper condition (Fig. 9).

It is necessary to check on the database of individual fragments descriptions of the model to preserve their authentic condition and restore the lost parts using modern building materials. The security passport must indicate which fragments are of historical value and which are less valuable, or fragments not of history but new buildings.

The certification of inherited monuments that have changed their architectural forms or elements during their lifetime is a different issue. Thus, as shown in the example of Saint Sophia's Cathedral in Kyiv (Fig. 2), the multi-layered historical content of the 3D model will reflect an animation of historical epochs and material culture - it will allow to study the composition of building materials by layers of structural elements in one object. The archaeological value of such a monument is increased because, in its example, modern methods of research were used (ultrasound, magnetic resonance, etc.). They show that it is possible to obtain standard characteristics of building materials and solutions for more accurate dating of other archeological objects of cultural heritage that have not survived until our time.

The proposed development of the BIM model of the monument to the level of 4D introduced in the study is possible not only in the presence of documented information and research on the past states of the object, but also under the condition of construction and hypothetical variants of the past configurations of the monument of a particular historical and architectural period. By adding to the altered elements information about the conditions in which this transformation took place (materials, construction technologies), the complete picture emerges for 
further research and the change of the hypothesis to axiom. For example, by comparing this information with other BIM models of certain period monuments and placements for which historical documents are confirmed.

HBIM 4D technology provides the ability to fill the timeline both in the 'past' time and 'as it is now,' as well as 'as it will be.' The last section is related to the management of the operation of conservation of the building and the reconstruction, restoration, or repair plan. Particularly important for the preservation of the monument is the ability to schedule repair work, pre-entered in the schedule information about the duration and durability of the construction materials used, and preliminary results of expert surveys. The schedule automatically highlights the expiration date for the use of a particular material or element.

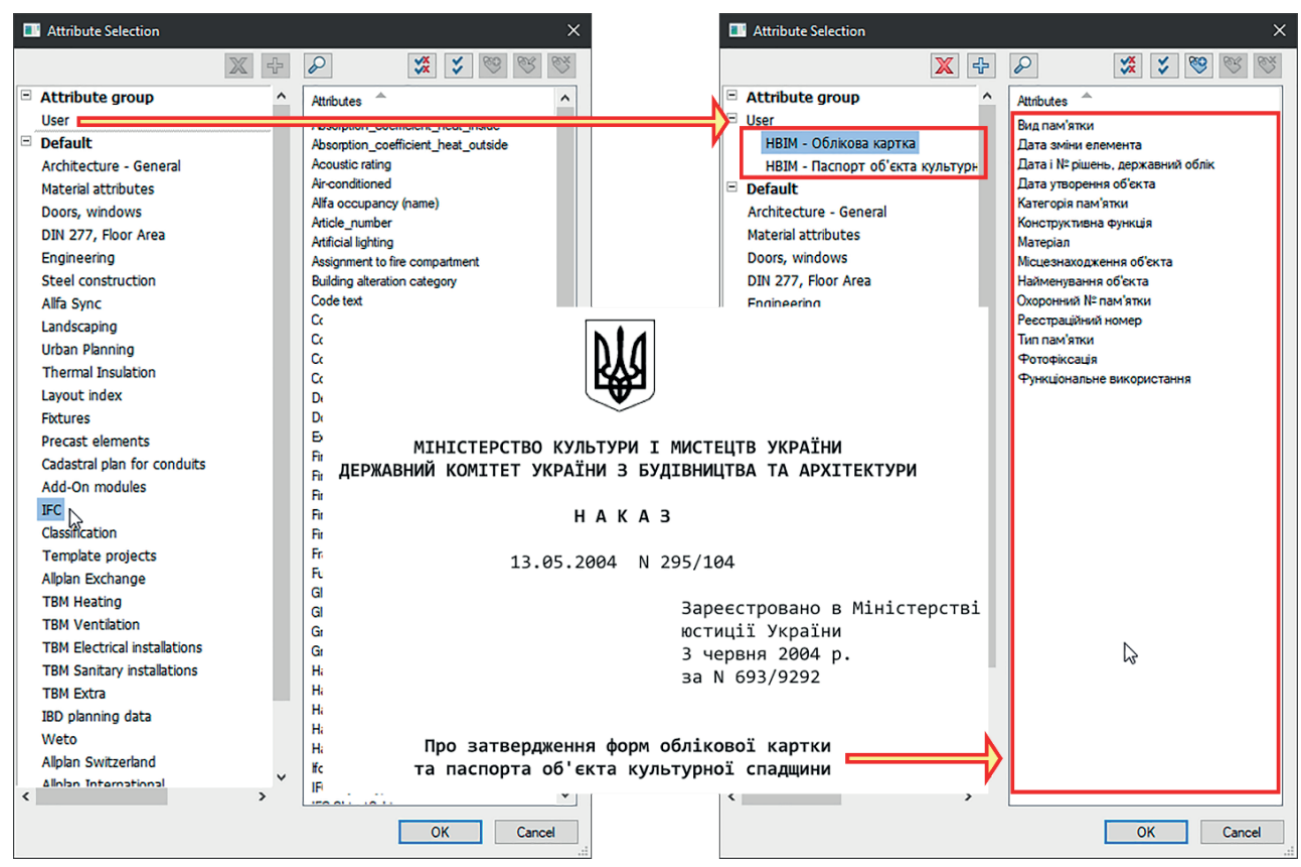

Fig. 10. Adaptive ability to assign attributes in Allplan to the attribute database of BIM element (Made in Allplan 2019 software with Partnership license) (own elaboration)

Modern technologies allow high-precision laser scanning to build a point cloud. The electronic version of the card has links to 3D types of BIM models, where specialists check the condition of the building, including minimal geometric deviations from previous inspection. For this purpose, the corresponding coordinates of the points cloud of the previous inspection date and the current one are compared.

When the global experience in cultural heritage monuments is generalized, it is possible to build an information database to describe the object and attach these characteristics to a specific volume of the BIM model. The study proves that the flexible attribute structure in Allplan is well-suited to creating such a base - a registration card and passport of a cultural heritage object (Fig. 10).

One of the technical features of using a BIM design program, such as Allplan, is to create model layers for architects (architects, BIM specialists, etc.) and research specialists 
(art critics, archaeologists, restorers, etc.). The general algorithm for creating a 3D model begins with the use of a scan of a building or structure; the second step is to build the architectural volume in the volume of the scanned shell. At this stage, BIM uses architectural and building elements embedded in the software in the design environment: wall, ceiling, column, beam, etc. From the name of each element at once, it is possible to derive certain information about the functional and spatial features of individual structures. That is, the first level of model information saturation is performed by indicating which elements make up the building.

LoI (Level of Object Information) as part of the general LOD (Level of Detail) concept should be spelled out in the EIR (Employer's Information Requirements) by the relevant specialists involved in the study, documentation, storage, or reconstruction of the architectural monument [10]. Thus, the object's electronic accounting card will have certain layers of specific non-graphic information corresponding to the LOD of the model itself.

Later in the restoration project, the research materials are aligned and combined with the $3 \mathrm{D}$ model. Technologically, this is solved by importing custom data from the cultural heritage description into the model in the BIM application environment. Imports can be performed sequentially - to each of the model elements, e.g., to each wall or column, or all model elements at once. It is clear that the second option requires a lot more support work to set up the links between the 3D data and the data from the security registry documents, which will be converted into a new model exchange format.

To establish such a connection, it is necessary to perform a manual task of certain properties and to check the export of attribute data of a 3D element through standard Allplan tools. This approach shows that it is possible to set up distributed data processing and creation of a standardized new card format (electronic data to BIM), objects of the virtual environment for research, restoration or reconstruction project, operational monitoring of cultural heritage objects (Figs. 11, 12, 13).

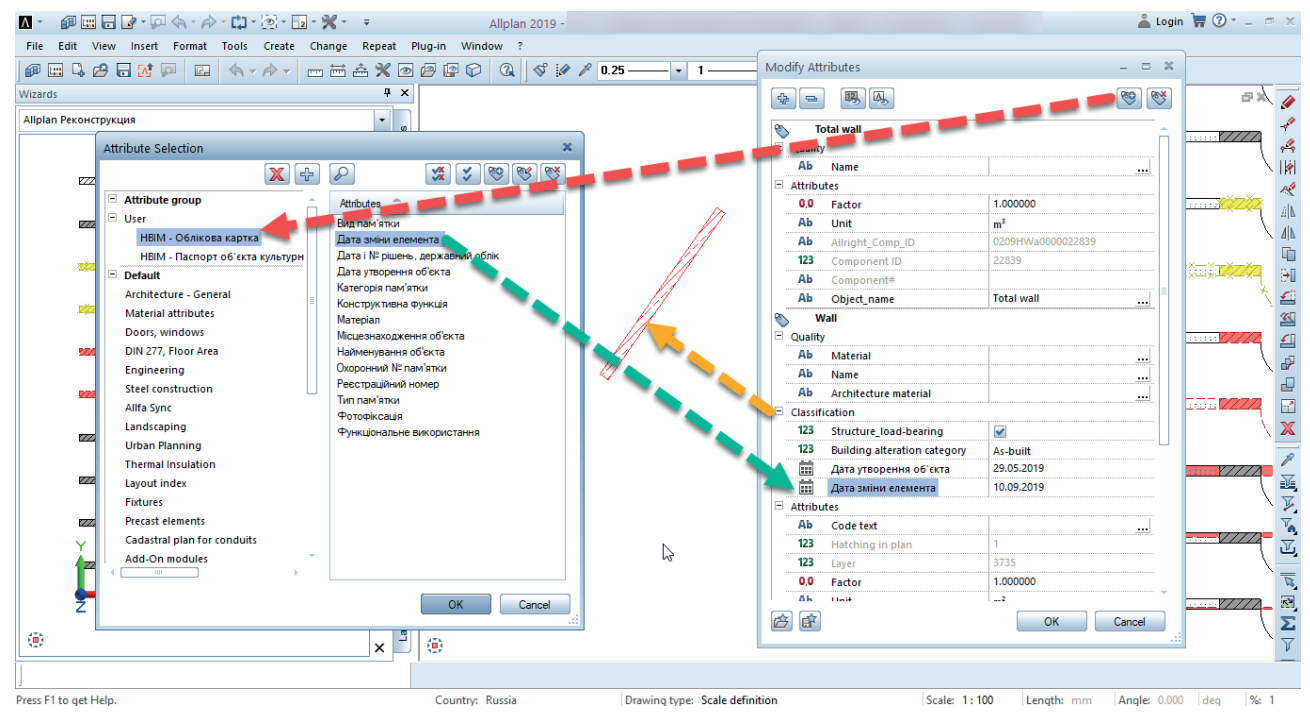

Fig. 11. HBIM - attributes to model elements added by the properties of the "registration form"(Made in Allplan 2019 software with Partnership license) (own elaboration) 
The sequence of operations can be changed with the number of layering components, automation of routine production operations and integration of the 'cloud' services.
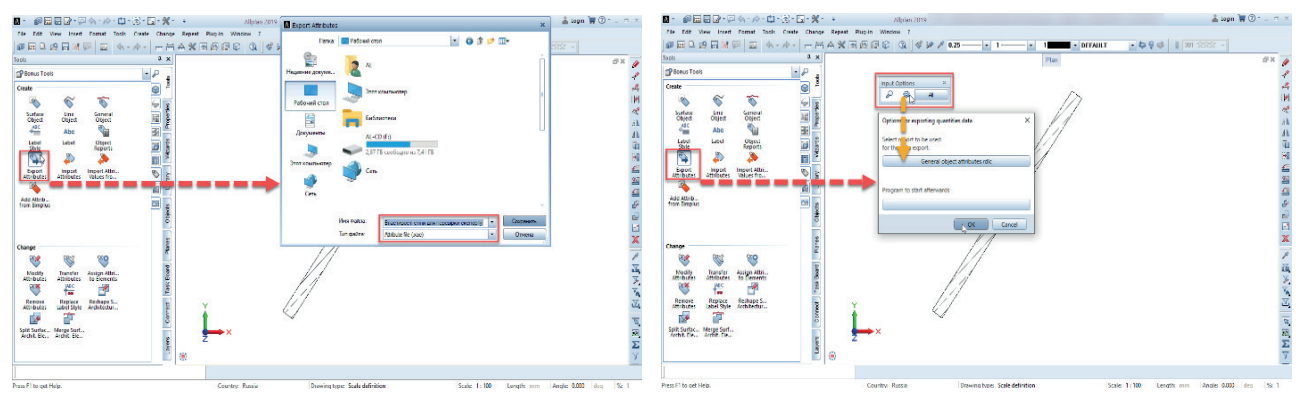

Fig. 12. HBIM data for each model element (Made in Allplan 2019 with Partnership license) (own elaboration)

Fig. 13. Attribute export settings to create a new sample account card (Made in Allplan 2019 software with Partnership license) (own elaboration)

In the future, it is possible to edit the data in tabular form (Fig. 14) by specialists in archeology, art, restoration, etc., since the saved attributes of elements (accounting card in the new format) of the model can be permanently replaced by the 'export-import' function in the interface of the BIM application Allplan (Fig. 11-14).

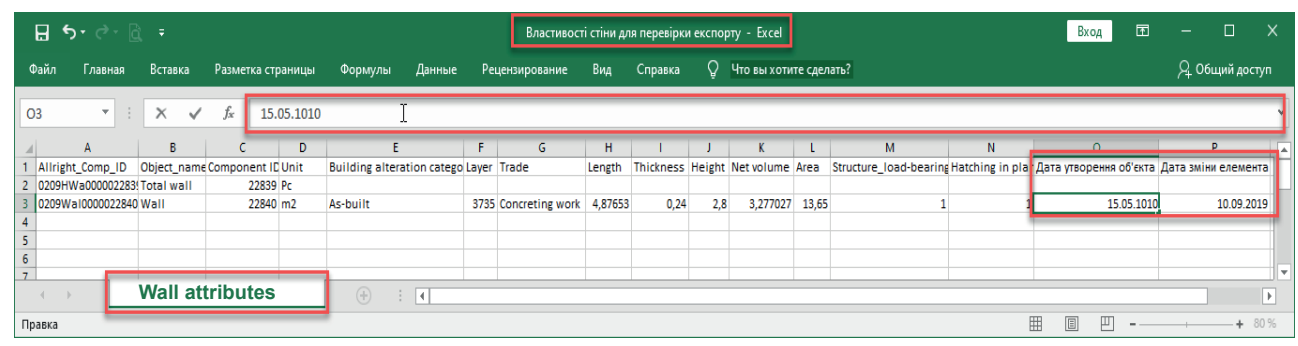

Fig. 14. HBIM - A new sample of registration card to describe architectural monuments (Made in MS Office 2019 software by for EDU) (own elaboration)

\section{Conclusion}

Presently, the use of information technologies (BIM) in the field of monitoring architectural objects of cultural heritage is a highly effective tool for their preservation. It presents a 3D model of the current state of the monument, preserves historical information about the object and its environment, develops documentation for restoration design, and so on. However, BIM-developments, such as simulation tools and software tools, are not used for filling the accounting cards and fixation changes of architectural monuments that took place during their operational period.

The use of these technologies to capture the architectural transformations of cultural heritage objects will allow the virtual display of their volumetric models at all stages of operational existence. It will also compare models of their original or current appearance with models of other periods of exploitation, to "go" to the level of integration with a "digital" historical environment to find out the dynamics of their development or decline. 
During this research, the authors concluded that it is possible to create documentation for storage and security activities in the form of a new type of accounting cards, such that they can transfer the data in the property of three-dimensional elements using BIM technology. The use of these technologies to capture the architectural transformations of cultural heritage objects will allow them to virtually display their volumetric models at all stages of the change of historical objects that occurred during their operational period.

This development direction provides prospects for deepening research in urban studies, architecture, sociology, and sustainable urban development. With big data processing capabilities, there will be correlated links between heterogeneous factors that contribute to varying accounting for human settlements. In addition, it looks possible for each historical site to be easier to control by applying a repair schedule. In this way, information on materials and structures used in a building can be processed both in a protective and scientific context.

Further research has two major goals: to deepen cooperation with institutes and departments, where archaeological, restoration, and art historians are trained to prepare general proposals for changes to the practice of monumental protection and use of the technology of BIM-documentation of cultural heritage monuments and to generalize the experience of documenting and using information technologies of foreign partners in the field of cultural heritage protection.

\section{Acknowledgements}

The authors would like to thank Prof. Mykola Bevz of LPNU for his advice and support of the idea behind this study and Allbaw software GmbH, Authorized Partner, a Nemetschek Group, for sharing their software license for the purpose of this research.

\section{References}

[1] Fortier, B., “L'atlas de Paris”, L'Architecture D'Aujourd'hui, vol. 265, (1989), pp.172-183.

[2] Megahed N.A., "Towards a theoretical framework for HBIM approach in historic preservation and management," Archnet-IJAR, vol. 9, no. 3, (2015), pp. 130-147. https://doi.org/10.26687/ archnet-ijar.v9i3.737

[3] Murphy C., Integration of Historic Building Information Modeling (HBIM) and 3D GIS for Recording and Managing Cultural Heritage Sites. 2012. Available: https://arrow.tudublin.ie/beschreccon [Access: 10 Jan 2020]

[4] Murphy M. et al., "Historic Building Information Modelling - Adding intelligence to laser and image based surveys of European classical architecture," ISPRS Journal of Photogrammetry and Remote Sensing, vol. 76, (2013), pp. 89-102. https://doi.org/10.1016/j.isprsjprs.2012.11.006

[5] "BIM for Heritage | Historic England", Available: https://historicengland.org.uk/images-books/ publications/bim-for-heritage/ [Accessed: 28 Apr 2020]

[6] Oreni D. et al., "Hbim for conservation and management of built heritage: Towards a library of vaults and wooden bean floors," in ISPRS Annals of the Photogrammetry, Remote Sensing and Spatial Information Sciences, (2013), vol. 2, no. 5/W1, pp. 215-221. https://doi.org/10.5194/ isprsannals-II-5-W1-215-2013

[7] Della Torre S., "Perspectives on Historic BIM Developments in Italy", AECbytes Viewpoint, 2016. Available: http://www.aecbytes.com/viewpoint/2016/issue_82.html [Accessed: 28 Apr 2020]

[8] Bilyk A.S., Belyaev M.A., "BIM modeling. Opportunities and Prospects in Ukraine", Industrial Construction and Engineering, vol. 2, (2015), pp.9-15. 
[9] Dotsenko T., Lyabakh M. and Paramonov O., KIEV: A Journey through Ancient City, Kiev House, Kyiv. (1998).

[10] "Levels of definition - Technical Support - NBS BIM Toolkit". Available: https://toolkit.thenbs. com/articles/levels-of-definition [Accessed: 04 May 2020]

[11] Kozlova T., Talapov V., "Experience of information modeling of architectural monuments", AMIT, vol.3(8), (2009). Available: https://docplayer.ru/51557731-Opyt-informacionnogo-modelirovaniya-pamyatnikov-arhitektury-t-i-kozlova-v-v-talapov.html [Accessed: 20 Aug 19]

[12] Kozlova T., Talapov V., "On the technique of BIM application in modeling of architectural monuments", AMIT, vol. 3 (12), (2010), Available: https://docplayer.ru/45661621-O-metodike-primeneniya-bim-v-modelirovanii-pamyatnikov-arhitektury-about-methods-of-using-bim-in-modeling-of-architectural-monuments.html [Accessed: 25 Aug 2019]

[13] Talapov V.V., "BIM technology and its connecting role for different architecture epochs", Balandinsky readings, vol. 10(2), (2015), pp.325-328.

[14] Uchański Ł. and Karsznia K., "The use of Terrestrial Laser Scanning for the purposes of preparing technical documentation in BIM technology," Budownictwo i Architektura, vol. 17, no. 3, (2018), pp. 189-199. https://doi.org/10.24358/Bud-Arch_18_173_14

[15] Sztwiertnia D. et al., "HBIM (heritage Building Information Modell) of the Wang Stave Church in Karpacz-Case Study," International Journal of Architectural Heritage, (2019). https://doi.org/ $10.1080 / 15583058.2019 .1645238$

[16] Kysil O., and Levchenko O., Mikhalchenko S., "Theoretical and methodological principles for the creation of a state database of building objects certified by the BIM technology", Web of Scholar, vol. 6(24), (2018). https://doi.org/10.31435/rsglobal_wos/12062018/5761

[17] Kysil O. and Naichuk N., "Digital registration cards of HBIM-based architectural heritage as a new stage of historic preservation of Krakow (Poland)." Modern Problems of Architecture and Urban Planning, vol. 0, no. 56, (2020), pp. 66-72. https://doi.org/10.32347/2077-3455.2020.56.66-72 